\title{
Docosahexaenoic acid-enriched egg consumption induces accretion of arachidonic acid in erythrocytes of elderly patients*
}

\author{
Marianne Payet ${ }^{1}$, Mohamed H. Esmail ${ }^{1}$, Elisabeth Polichetti ${ }^{2}$, Gaël Le Brun ${ }^{2}$, \\ Lounès Adjemout $^{3}$, Gérard Donnarel ${ }^{3}$, Henri Portugal ${ }^{1}$ and Gérard Pieroni ${ }^{1 \dagger}$ \\ ${ }^{1}$ I.N.S.E.R.M. U476, Faculté de Médecine, 27 Bd Jean Moulin, 13385 Marseille cedex 05, France \\ ${ }^{2}$ GLON SANDERS, Pontivy, France \\ ${ }^{3}$ Centre Gérontologique Départemental, Marseille, France
}

(Received 19 September 2003 - Revised 22 January 2004 - Accepted 29 January 2004)

\begin{abstract}
Many studies in humans volunteers have shown that dietary docosahexaenoic acid (DHA) supplied as triacylglycerol can increase DHA levels in blood lipids but often strongly decreases those of arachidonic acid (AA). The aim of the present study was to determine the effect of dietary supplementation with egg-yolk powder enriched in DHA, corresponding to the French recommended dietary allowance for DHA, on the blood lipid status of an elderly population. Institutionalised elderly individuals aged between 63 and 93 years consumed an egg product enriched in DHA $(150 \mathrm{mg} / \mathrm{d})$ once daily for 9 months. Plasma lipids and the fatty acid composition of erythrocyte membranes were determined every 3 months. The supplementation induced an increase in the PUFA content of plasma and erythrocyte membranes which was +14.5 and $+25.3 \%$, respectively, at 9 months. This effect was mainly due to the level of DHA and, unexpectedly, to that of AA which continuously increased. This increase in AA was the result of an increased dietary intake $(+50 \mathrm{mg} / \mathrm{d})$ and very probably of an increased biosynthesis as demonstrated by the behaviour of di-homo- $\gamma$-linolenic acid. The supplementation resulted in a blood PUFA status comparable with that of young healthy controls. The data are consistent with a strong regulatory action of the dietary treatment on the subjects' lipid metabolism.
\end{abstract}

Docosahexaenoic acid: Arachidonic acid: Enriched egg yolk: Elderly

During the last decade, much research has focused on the role of a balanced dietary supply of PUFA of the $n-6$ and $n-3$ families and of carbon chain length $\mathrm{C}_{18}$ to $\mathrm{C}_{22}$ in maintaining good health. Among the dietary PUFA, those of the $n-3$ family are suspected to be supplied in too low amounts in the populations of Western countries (Simopoulos, 1991). The capacity of man to convert $\alpha$-linolenic acid into eicosapentaenoic acid (EPA) and docosahexaenoic acid (DHA) is low (Brenner, 1977; Burdge et al. 2002; Pawlosky et al. 2003), and the major controlling factor of this conversion, $\Delta 6$-desaturase, has been reported to be less efficient with ageing (De Gomez-Dumm \& Brenner, 1974; Darcet \& Driss, 1985). Elderly individuals represent a group at risk of nutritional imbalance due to altered food choices and low energy intakes (Munro \& Danford, 1989). Hence, in Western elderly populations a low $n-3$ PUFA status is very likely and this may have significant negative consequences since the status of these fatty acids may be very critical for health. Since the pioneering works of Dyerberg and Bang (Dyerberg et al. 1978) on the relationship between $n-3$ PUFA and cardiovascular diseases, beneficial effects of $n-3$ PUFA in the treatment of arthritis, cancer, diabetes, lupus and psoriasis, which are common diseases in elderly individuals, have been reported (Simopoulos, 1991). A low serum DHA level has been reported as a significant risk factor for the development of Alzheimer's disease (Kyle et al. 1999). Sudden cardiac death in man has been associated with a higher arachidonic acid (AA):DHA ratio than that observed in individuals of the same age who died in accidents (Gudbjarnason et al. 1989). Among a population of Mediterranean patients we have observed that low levels of DHA and docosapentaenoic acid in erythrocytes correlate with coronary artery disease (Paganelli et al. 2001). A study by Asciutti-Moura et al. (1988) concluded that French institutionalised elderly individuals are deficient in circulating essential fatty acids, which appears to be caused by both diet and metabolism. In order to prevent such negative effects, the French recommended dietary allowance (RDA) for elderly individuals has been fixed at $100 \mathrm{mg}$ DHA/d (Martin, 2001).

The focus of most of the supplementation studies in human subjects has been on the use of fish oils or of algae triacylglycerol rich in DHA, and few studies have addressed the question of the vehicle. Interestingly, in

\footnotetext{
Abbreviations: AA, arachidonic acid; DHA, docosahexaenoic acid; DHGLA, di-homo- $\gamma$-linolenic acid; EPA, eicosapentaenoic acid; RDA, recommended dietary allowance.

*Presented as an oral communication at ISSFAL Fifth Congress, 7-11 May 2002, Montreal, Canada.

$†$ Corresponding author: Dr Gérard Pieroni, fax + 334917821 01, email gerard.pieroni@medecine.univ-mrs.fr
} 
human subjects (Carnielli et al. 1998), it has been shown that the intestinal absorption of DHA provided in the form of egg phospholipids is greater than in the form of triacylglycerols. It has also been shown that $\left[{ }^{13} \mathrm{C}\right] \mathrm{DHA}$ in the form of phospholipids is more efficiently taken up by erythrocytes, and putatively by the brain, than DHA in the form of triacylglycerols (Lemaitre-Delaunay et al. 1999). Furthermore, since DHA in phospholipids is more resistant to oxidation than that in triacylglycerol (Song et al. 1997), the phospholipid form seems to be an interesting vehicle to supply DHA compared with triacylglycerols.

DHA-enriched eggs contain most of their DHA in the form of phospholipid (Bernard, 1995) and manipulation of the feed of hens easily enables the production of eggs containing $100 \mathrm{mg}$ or more of DHA per yolk (Van Elswyk, 1997).

The aim of the present study was to document in a Mediterranean elderly population the effects on the blood lipid composition of 9 months' dietary supplementation of DHA corresponding to the French RDA, when given in the form of egg lipids, i.e. mainly in the form of phospholipids.

\section{Subjects and methods}

\section{Subjects and study design}

The study was carried out on a group of elderly individuals living in a nursing home in Marseilles (France). Individuals with Alzheimer's disease or dementia were excluded. Before inclusion in the study, they were asked to give their written agreement and in some cases that of their family was obtained as well. Blood was collected from sixty-five individuals housed in the same building and sharing the same food. The control groups consisted of individuals not included in the dietary intervention whose blood analyses were performed at 0 months and at 6 months after the beginning of the study. These were: at 0 months, sixteen individuals (six females (91.4 (SD 3.9) years) and ten males (75.4 (SD 10.4) years); at 6 months, thirteen individuals (nine females (79 (SD 13.0) years) and four males (75.3 (SD 4.6) years). Thirty-six ambulatory subjects were recruited for the 9-month supplementation study. During the course of the study thirteen individuals dropped out: eight for individual reasons; two because of medical conditions; two went back home; one died. Twenty-three individuals aged between 63 and 93 years completed the study, fifteen females (82.9 (SD 7.0) years) and eight males (75.5 (SD 7.7) years). The study subjects were asked to consume (once daily) a dessert made with the equivalent of one egg enriched in DHA, for 9 months. This dessert replaced the one usually provided which was very often a dairy product (yoghurt) or other dessert prepared with a normal egg. Compliance with the regimen was checked during various periods. The subjects ate an average of $70 \%$ of the dessert, enabling the calculation of the daily extra average quantities of fatty acids ingested. These were about $150 \mathrm{mg}$ DHA, about $50 \mathrm{mg}$ AA and about $15 \mathrm{mg}$ EPA. The composition of the meals and the quantities consumed were obtained from the dietitians; on a non-supplemented diet, the maximal average daily quantities of DHA and AA were 90 and $100 \mathrm{mg}$, respectively, as calculated by means of food composition tables (Klepping et al. 1990; Feinberg et al. 1991). Blood samples were collected by venepuncture after a $12 \mathrm{~h}$ overnight fast at 0,3,6 and 9 months. On a few occasions, not enough blood was obtained to make all analyses; a sample was not obtained at 3 months from one ill individual. The study protocol was approved by the local ethics committee 'Comité Consultatif de Protection des Personnes dans la Recherche Biomédicale' of Marseilles 1.

Since we dealt with egg-yolk powder enriched in DHA (about $4 \%(\mathrm{w} / \mathrm{w})$ in the fatty acids), while control eggyolk powders contain about $0.5 \%$ DHA and we wanted to investigate the effect of low doses of DHA, we decided to run the study with a single dose, each patient being his or her own control. At the beginning of the study we were unable to exclude the possibility that significant changes in fatty acid compositions would be obtained by using, as the control test, levels of $0.5 \%$ DHA. We felt we would have a better chance of detecting changes by using the test diet levels we chose, about $4 \%(\mathrm{w} / \mathrm{w})$ DHA in the fatty acids, and comparing it with the situation before administering the supplementation. Furthermore, the choice was made not to run a parallel design in order to avoid any possible exchange among the supplements between individuals sharing their meals at the same table.

\section{Materials}

The diet of laying hens was supplemented with fish oil containing almost equal amounts of DHA and EPA (Van Elswyk, 1997). Egg-yolk powder rich in DHA was prepared (GLON S.A., Pontivy, France). Its composition is given in Table 1. Most of the DHA (83\%) in this egg-yolk powder is localised to the $s n-2$ position of phospholipids, in almost equal amounts in phosphatidylethanolamine and phosphatidylcholine. This egg-yolk powder was incorporated as an ingredient of various desserts prepared weekly by 'Les Repas Santé' (Beaune, France). The composition of these desserts is given in Table 2. Boron trifluoride, $14 \%$ in methanol, was obtained from Sigma (St Quentin Fallavier, France). Reagent-grade solvents were purchased from Carlo Erba (Val de Reuil, France).

\section{Analysis of the egg-yolk lipids}

Lipids were extracted from the egg-yolk powder according to the method of Bligh \& Dyer (1959). Cholesterol content was determined by an enzymic method (CHOD-PAP; Roche Diagnostics Corp., Indianapolis, IN, USA) on the total lipid extract. The composition of the $s n$-2-fatty acids of the phospholipids and that of the corresponding lyso compounds was determined after snake venom hydrolysis according to the method of Wells \& Hanahan (1969).

\section{Biochemical analysis}

Biochemical measurements in plasma included total cholesterol, LDL-cholesterol, HDL-cholesterol, triacylglycerols, phospholipids, lipidograms, apo $\mathrm{A}_{1}$ and apo B. Haematological analyses included erythrocyte count, 
Table 1. Lipid composition (\% (w/w) total fatty acids) of egg-yolk powder enriched in docosahexaenoic acid (DHA)*

\begin{tabular}{|c|c|c|c|c|c|}
\hline & \multirow[b]{2}{*}{ Total lipids } & \multirow[b]{2}{*}{ Phospholipids } & \multirow[b]{2}{*}{ Neutral lipids } & \multicolumn{2}{|l|}{ Composition } \\
\hline & & & & $\mathrm{mg} / \mathrm{g}$ egg yolk powder & $\%$ \\
\hline $16: 0$ & 25.5 & 30.9 & 24.4 & & \\
\hline 18:0 & 7.55 & $12 \cdot 5$ & $5 \cdot 56$ & & \\
\hline $18: 1 n-9$ & $40 \cdot 9$ & 23.9 & $45 \cdot 9$ & & \\
\hline $18: 2 n-6$ & $16 \cdot 6$ & $12 \cdot 2$ & $15 \cdot 4$ & & \\
\hline $18: 3 n-3$ & 0.7 & 0.03 & 0.91 & & \\
\hline $20: 4 n-6$ & 1 & $3 \cdot 18$ & 0.26 & & \\
\hline $20: 5 n-3$ & 0.44 & 0.95 & 0.16 & & \\
\hline $22: 5 n-3$ & 0.78 & $1 \cdot 13$ & 0.73 & & \\
\hline $22: 6 n-3$ & 3.96 & 12.5 & 0.67 & & \\
\hline DHA:EPA & 9 & $13 \cdot 2$ & $4 \cdot 2$ & & \\
\hline Lipids & & & & 632 & $100 \dagger$ \\
\hline Phospholipids & & & & 174 & $83 \dagger$ \\
\hline Cholesterol & & & & 32 & $-\dagger$ \\
\hline Triacylglycerols & & & & 426 & $16 \dagger$ \\
\hline \multicolumn{6}{|l|}{ Phospholipids (\% by w) } \\
\hline Phosphatidylcholine & & & & & 71 \\
\hline Phosphatidylethanolamine & & & & & 24 \\
\hline \multicolumn{6}{|l|}{ DHA in phospholipid fatty acids } \\
\hline Phosphatidylcholine & & & & & 9 \\
\hline Phosphatidylethanolamine & & & & & 26 \\
\hline \multicolumn{6}{|c|}{ Percentage DHA bound to $s n-2$ position of phospholipids } \\
\hline Phosphatidylcholine & & & & & 98 \\
\hline Phosphatidylethanolamine & & & & & 99.4 \\
\hline
\end{tabular}

EPA, eicosapentaenoic acid.

${ }^{*}$ For details of procedures, see pp. 790-792.

†DHA \%.

haemoglobin, packed cell volume, mean corpuscular volume, mean corpuscular haemoglobin, platelet count, leucocyte count, lymphocytes, monocytes, neutrophils, eosinophils and basophils. These parameters were determined at $0,3,6$ and 9 months.

\section{Preparation of erythrocyte membranes}

Erythrocyte membranes were prepared according to the procedure of Pekiner \& Pennock (1995). Blood (9 ml) was centrifuged at $4^{\circ} \mathrm{C}$ for $15 \mathrm{~min}$ at $1000 \mathrm{~g}$. The erythrocytes were lysed with $40 \mathrm{ml}$ tris(hydroxymethyl)-aminomethane $(0.011 \mathrm{M})$, centrifuged at $4^{\circ} \mathrm{C}$ for $30 \mathrm{~min}$ at $36900 \mathrm{~g}$ (Beckman centrifuge, rotor J.A 25.50; Beckman Coulter France, Villepinte, France), and the supernatant fractions discarded. This operation was usually repeated five times until the supernatant fraction was clear.

\section{Analysis of fatty acid composition}

Lipids were extracted from the plasma or the erythrocyte membranes according to Bligh \& Dyer (1959) and

Table 2. Composition of desserts enriched in docosahexaenoic acid*

\begin{tabular}{|c|c|c|c|c|c|c|}
\hline \multirow{2}{*}{ Dessert. . } & \multicolumn{2}{|c|}{ Caramel cream } & \multicolumn{2}{|c|}{ Vanilla cream } & \multicolumn{2}{|c|}{ Chocolate-pear cream } \\
\hline & $\% †$ & $\mathrm{mg} /$ Serving & $\% †$ & $\mathrm{mg} /$ Serving & $\% \dagger$ & mg/Serving \\
\hline Proteins $(\mathrm{g})$ & \multicolumn{2}{|c|}{6.88} & \multicolumn{2}{|c|}{$6 \cdot 88$} & \multicolumn{2}{|c|}{6.63} \\
\hline Lipids (g) & \multirow{2}{*}{\multicolumn{2}{|c|}{$\begin{array}{l}10 \cdot 7 \\
13.2\end{array}$}} & \multicolumn{2}{|c|}{$10 \cdot 7$} & \multicolumn{2}{|c|}{11.4} \\
\hline Carbohydrates (g) & & & \multicolumn{2}{|c|}{$13 \cdot 2$} & \multicolumn{2}{|c|}{$22 \cdot 3$} \\
\hline Cholesterol (mg) & \multicolumn{2}{|c|}{256} & \multirow{2}{*}{\multicolumn{2}{|c|}{$\begin{array}{l}256 \\
741\end{array}$}} & \multicolumn{2}{|c|}{247} \\
\hline Energy (kJ) & \multicolumn{2}{|c|}{741} & & & & \\
\hline \multicolumn{7}{|c|}{ Distribution of fatty acids } \\
\hline $16: 0$ & $25 \cdot 6$ & 2360 & $26 \cdot 2$ & 2420 & 23.5 & 2300 \\
\hline $18: 0$ & 8.72 & 800 & 8.80 & 810 & 7.24 & 710 \\
\hline $18: 1 n-9$ & $37 \cdot 3$ & 3400 & $36 \cdot 3$ & 3360 & $41 \cdot 1$ & 4030 \\
\hline $18: 2 n-6$ & $10 \cdot 7$ & 1000 & 10 & 900 & 14.6 & 1380 \\
\hline $18: 3 n-3$ & 0.75 & 69 & 0.69 & 66 & 0.81 & 80 \\
\hline $20: 4 n-6$ & 0.76 & 70 & 0.73 & 70 & 0.37 & 37 \\
\hline $20: 5 n-3$ & 0.20 & 19 & $0 \cdot 18$ & 17 & 0.30 & 29 \\
\hline $22: 5 n-3$ & 0.20 & 19 & $0 \cdot 18$ & 17 & 0.30 & 29 \\
\hline $22: 6 n-3$ & $2 \cdot 17$ & 200 & 1.92 & 180 & $2 \cdot 80$ & 280 \\
\hline
\end{tabular}

${ }^{*}$ For details of procedures, see pp. 790-792.

† Percentage $(w / w)$ total fatty acids. 
Kates (1972). Butylated hydroxytoluene $(50 \mu \mathrm{M})$ was present at all stages of the process. Fatty acid methyl esters were prepared by incubation with $14 \%$ boron trifluoride methanol-methanol $(1: 1, \mathrm{v} / \mathrm{v})$ at $100^{\circ} \mathrm{C}$ for $30 \mathrm{~min}$ according to the method of Ohta et al. (1990). They were analysed by GC on a $25 \mathrm{~m} \times 0.22 \mathrm{~mm}$ capillary column (SGE, BPX 70, $0.25 \mu \mathrm{m}$ ) in a Perkin-Elmer Autosystem XL equipped with a flame-ionisation detector and Turbochrom software (Perkin-Elmer Instruments, Norwalk, CT, USA). Fatty acid methyl esters were identified by comparing their retention times to those of standards.

\section{Statistical analysis}

Statistical significance was determined by using repeatedmeasures ANOVA, and a $P$ value of $<0.05$ (Fisher's protected least significant difference test) was taken to indicate statistical significance. Stat view SE +1.03 software (SAS Institute Inc., Cary, NC, USA) was used.

\section{Results}

\section{Behaviour of the control groups}

Table 3 presents the fatty acid composition of the plasma and erythrocyte membranes lipids of the control groups at 0 and 6 months. No significant difference was observed among all their fatty acid compositions. In addition no significant difference was detected between the two groups for all the other biochemical parameters.

\section{Biochemical analysis}

Data concerning plasma lipids are reported in Table 4. There were no significant effects of dietary supplementation on cholesterol concentrations. The concentrations of triacylglycerols and phospholipids showed a slight and transient decrease at 6 months. No significant change in any of the other biochemical parameters was observed (data not shown).

\section{Average fatty acid composition of plasma}

The administration of DHA supplementation for 9 months induced, as shown in Table 5, a 36.5\% increase in plasma $n$-3 PUFA, an $11.7 \%$ increase in $n$ - 6 PUFA, and an $11.8 \%$ decrease in saturated fatty acids. In the $n-6$ family, AA increased significantly, up to $+32 \%$, at the end of the study. In the $n-3$ family, the percentage of EPA $(+70 \%)$ increased significantly, and DHA was significantly higher $(+60 \%)$ after 3 months of supplementation. The trend of palmitic acid was to decrease with time while that of oleic acid and AA was to increase. The DHA:AA ratio reflected the variations of both fatty acids; it increased during the first period due to the DHA content and then decreased due to the continuous rise of AA.

\section{Average fatty acid composition of erythrocyte membranes}

As shown in Table 6, the fatty acid composition of erythrocyte membranes was altered by the treatment: $n$-3 PUFA increased $(+19.5 \%)$ at 9 months. Docosapentaenoic acid and EPA increased $(+13$ and $+20 \%$, respectively) after 3 months, then decreased ( -11 and $-9 \%$, respectively). Meanwhile DHA increased (+57\%) after 3 months of supplementation and then plateaued. The supplementation induced a $27.8 \%$ increase in $n-6$ PUFA. AA increased by $+42 \%$ at 9 months, and $20: 3 n-6$ (di-homo- $\gamma$-linolenic acid; DHGLA) by $+23 \%$ at 6 months. Interestingly, saturated fatty acids showed two different trends during dietary

Table 3. Fatty acid status (\% (w/w) total fatty acids) in plasma and erythrocyte membranes of control groups (Mean values and standard deviations)

\begin{tabular}{|c|c|c|c|c|c|c|c|c|}
\hline \multirow{3}{*}{$\begin{array}{l}\text { Group... } \\
\text { Fatty acid }\end{array}$} & \multicolumn{4}{|c|}{ Plasma } & \multicolumn{4}{|c|}{ Erythrocyte membranes } \\
\hline & \multicolumn{2}{|c|}{0 months ( $n 16)$} & \multicolumn{2}{|c|}{6 months (n13) } & \multicolumn{2}{|c|}{0 months ( $n 16)$} & \multicolumn{2}{|c|}{6 months (n 13) } \\
\hline & Mean & SD & Mean & SD & Mean & SD & Mean & SD \\
\hline $\mathrm{AA}$ & 6.43 & $1 \cdot 33$ & $6 \cdot 61$ & 0.93 & 12.46 & $2 \cdot 11$ & $13 \cdot 77$ & 1.32 \\
\hline EPA & 0.71 & 0.22 & 0.66 & 0.12 & 1.07 & 0.81 & 0.69 & 0.11 \\
\hline DHA & $2 \cdot 21$ & 0.50 & 2.41 & 0.58 & 4.83 & $1 \cdot 20$ & 5.04 & 0.92 \\
\hline
\end{tabular}

AA, arachidonic acid; EPA, eicosapentaenoic acid; DHA, docosahexaenoic acid

${ }^{*}$ For details of subjects and procedures, see pp. 790-792.

Table 4. Effect of supplementation on plasma concentrations of cholesterol, triacylglycerols and phospholipids* (Mean values and standard deviations)

\begin{tabular}{|c|c|c|c|c|c|c|c|c|}
\hline & \multicolumn{2}{|c|}{0 months ( $n 21)$} & \multicolumn{2}{|c|}{3 months (n 18) } & \multicolumn{2}{|c|}{6 months ( $n 20)$} & \multicolumn{2}{|c|}{9 months ( $n$ 23) } \\
\hline & Mean & SD & Mean & $\mathrm{SD}$ & Mean & SD & Mean & $\mathrm{SD}$ \\
\hline Cholesterol (mм) & $5 \cdot 45$ & 0.82 & $5 \cdot 38$ & 0.80 & 5.47 & 0.83 & 5.57 & 0.90 \\
\hline Triacylglycerols (mM) & $1 \cdot 17^{\mathrm{a}, \mathrm{b}}$ & 0.73 & $1 \cdot 16^{a}$ & 0.38 & $1.05^{\mathrm{b}}$ & 0.36 & $1 \cdot 16^{\mathrm{a}, \mathrm{b}}$ & 0.44 \\
\hline Phospholipids (mM) & $3 \cdot 12^{\mathrm{a}, \mathrm{b}}$ & 0.41 & $3 \cdot 13^{a}$ & 0.37 & $3.04^{b}$ & 0.34 & $3.03^{b}$ & 0.40 \\
\hline
\end{tabular}

${ }_{\mathrm{a}, \mathrm{b}}$ Mean values within a row with unlike superscript letters were significantly different $(P<0.05)$.

${ }^{*}$ For details of subjects and procedures, see pp. 790-792. 
Table 5. Effect of supplementation on the fatty acid composition $\left(\%(\mathrm{w} / \mathrm{w})\right.$ total fatty acids) of plasma total lipids $(n 21)^{*}$ (Mean values and standard deviations)

\begin{tabular}{|c|c|c|c|c|c|c|c|c|}
\hline \multirow[b]{2}{*}{ Fatty acid } & \multicolumn{2}{|c|}{0 months } & \multicolumn{2}{|c|}{3 months } & \multicolumn{2}{|c|}{6 months } & \multicolumn{2}{|c|}{9 months } \\
\hline & Mean & SD & Mean & SD & Mean & SD & Mean & SD \\
\hline $16: 0$ & $21.96^{a}$ & 1.45 & $18 \cdot 98^{b}$ & 1.89 & $17 \cdot 2^{\mathrm{C}}$ & 1.13 & $17 \cdot 11^{c}$ & $1 \cdot 36$ \\
\hline $18: 0$ & $7 \cdot 14^{a}$ & 0.69 & $7 \cdot 19^{a}$ & $1 \cdot 31$ & $7 \cdot 64^{a}$ & 1.06 & $8.55^{\mathrm{b}}$ & 0.93 \\
\hline $18: 1 n-9$ & $19 \cdot 54^{a}$ & 1.60 & $19 \cdot 95^{\mathrm{a}}$ & 1.99 & $22 \cdot 99^{b}$ & 3.56 & $23.55^{b}$ & 2.44 \\
\hline $18: 2 n-6$ & $23.97^{a, b}$ & 4.06 & $22 \cdot 02^{b}$ & 3.03 & $24.08^{a}$ & 3.36 & $25 \cdot 18^{a}$ & 6.97 \\
\hline $20: 3 n-6$ & $1 \cdot 83^{\mathrm{a}}$ & 0.45 & $2 \cdot 23^{b}$ & 0.36 & $2 \cdot 31^{b}$ & 0.42 & $2 \cdot 31^{b}$ & 0.37 \\
\hline $20: 4 n-6$ & $6 \cdot 43^{a}$ & $1 \cdot 33$ & $6 \cdot 96^{a}$ & 1.53 & $8.08^{b}$ & 1.80 & $8 \cdot 50^{b}$ & 1.76 \\
\hline $20: 5 n-3$ & $0.71^{a}$ & 0.22 & $1 \cdot 18^{b}$ & 0.46 & $1.20^{b}$ & 0.44 & $1 \cdot 21^{b}$ & 0.44 \\
\hline $22: 5 n-3$ & $1 \cdot 22^{\mathrm{a}, \mathrm{c}, \mathrm{d}}$ & 0.35 & $1.62^{b}$ & 0.40 & $1 \cdot 33^{c}$ & 0.52 & $1.03^{d}$ & 0.32 \\
\hline $22: 6 n-3$ & $2 \cdot 21^{a}$ & 0.50 & $3.55^{b}$ & 0.51 & $3 \cdot 30^{b}$ & 0.90 & $3.41^{b}$ & 1.03 \\
\hline DHA:AA & $0.36^{a}$ & 0.16 & $0.53^{b}$ & 0.14 & $0.42^{a}$ & 0.12 & $0.40^{a}$ & 0.08 \\
\hline
\end{tabular}

DHA, docosahexaenoic acid; AA, arachidonic acid.

a,b,c,d Mean values within a row with unlike superscript letters were significantly different $(P<0.05)$.

${ }^{*}$ For details of subjects and procedures, see pp. 790-792.

supplementation. Palmitic acid decreased while stearic acid increased resulting in an almost constant percentage of saturated fatty acids. Of interest is the behaviour of the relative standard deviation of the sum of all fatty acids. Its value decreased continuously from $14.21 \%$ at the start of the study to $13.59,10.39$ and $9.16 \%$ at 3,6 , and 9 months respectively.

\section{Behaviour of individual fatty acids values in plasma and erythrocyte lipids}

The data suggest a regulatory action of the dietary treatment on the subjects' lipid metabolism. This prompted us to focus our attention on individual responses to the diet. We plotted for each fatty acid the variation in its percentage after 3 months of supplementation as a function of its initial percentage. This was done for the fatty acids of the plasma and the erythrocyte membranes. Fig. 1 presents these variations in the case of AA and DHA for erythrocyte membranes. These data can be tentatively described by a linear relationship. The validity of this model can be evaluated by the $R$ and $P$ values which are associated with the parameters of the linear regression, the abscissa at the origin and the sign and value of the proportional parameter. Furthermore one can calculate the number of cases for which an increase was measured, $(\Delta>0)$, as well as that for which there was a decrease $(\Delta<0)$. Table 7 presents these data. Concerning the plasma, in all cases the sign of the proportional parameter is negative which indicates that the lower increases were in all situations associated with the higher initial values. With the exception of AA, the representation fits well with a linear model. Of importance are the DHGLA, AA and DHA data, which show the highest ratios of increased cases; 17:20, 16:21 and 15:21 respectively. The general trend is a balanced number of cases for which a reduction of the higher values is accompanied by an increase of the lower ones $(\Delta>0 \approx \Delta<0)$ except for these three fatty acids.

For the fatty acids of the erythrocyte membranes the proportional parameter is negative confirming the general trend noticed previously. With no exceptions, the representation of the data fits with a linear model; all $P$ values were

Table 6. Effect of the supplementation on the fatty acid composition (\% (w/w) total fatty acids) of erythrocyte membrane lipids $\left(n\right.$ 23) ${ }^{*}$

(Mean values and standard deviations)

\begin{tabular}{|c|c|c|c|c|c|c|c|c|}
\hline \multirow[b]{2}{*}{ Fatty acid } & \multicolumn{2}{|c|}{0 months } & \multicolumn{2}{|c|}{3 months } & \multicolumn{2}{|c|}{6 months } & \multicolumn{2}{|c|}{9 months } \\
\hline & Mean & SD & Mean & SD & Mean & SD & Mean & SD \\
\hline $16: 0$ & $20 \cdot 33^{a}$ & $1 \cdot 88$ & $15 \cdot 16^{b}$ & $1 \cdot 84$ & $14 \cdot 44^{\mathrm{b}}$ & $1 \cdot 13$ & $14 \cdot 72^{b}$ & $1 \cdot 19$ \\
\hline $18: 0$ & $12 \cdot 92^{\mathrm{a}}$ & 2.04 & $15 \cdot 80^{b}$ & 1.67 & $16 \cdot 31^{b}$ & 0.86 & $16 \cdot 14^{\mathrm{b}}$ & 0.85 \\
\hline $18: 1 n-9$ & $13 \cdot 23^{a}$ & $1 \cdot 22$ & $13 \cdot 93^{b}$ & 1.41 & $14 \cdot 81^{\mathrm{c}}$ & 0.86 & $14 \cdot 79^{c}$ & 0.76 \\
\hline $18: 2 n-6$ & $8 \cdot 47^{a, b}$ & 1.53 & $8 \cdot 35^{a}$ & $1 \cdot 35$ & $9 \cdot 32^{b}$ & 1.99 & $9 \cdot 25^{\mathrm{b}}$ & 1.47 \\
\hline $20: 3 n-6$ & $1 \cdot 80^{\mathrm{a}}$ & 0.69 & $2 \cdot 03^{a, b}$ & 0.38 & $2 \cdot 21^{\mathrm{b}}$ & 0.49 & $2 \cdot 11^{\mathrm{b}}$ & 0.41 \\
\hline $20: 4 n-6$ & $12 \cdot 78^{\mathrm{a}}$ & 1.47 & $16 \cdot 25^{\mathrm{b}}$ & 2.28 & $16 \cdot 88^{b}$ & 1.64 & $18 \cdot 11^{\mathrm{c}}$ & 1.46 \\
\hline $20: 5 n-3$ & $1 \cdot 12^{a, b}$ & 0.74 & $1.35^{\mathrm{b}}$ & 0.55 & $1 \cdot 10^{a, b}$ & 0.28 & $1.02^{a}$ & 0.23 \\
\hline $22: 5 n-3$ & $4.07^{a}$ & 0.78 & $4 \cdot 61^{b}$ & 0.80 & $4 \cdot 08^{a}$ & 0.65 & $3 \cdot 61^{\mathrm{c}}$ & 0.79 \\
\hline $22: 6 n-3$ & $4 \cdot 86^{a}$ & 0.96 & $7 \cdot 64^{b}$ & $1 \cdot 31$ & $7 \cdot 35^{b}$ & 1.09 & $7 \cdot 38^{b}$ & 0.82 \\
\hline DHA:AA & $0.39^{a}$ & 0.10 & $0.48^{b}$ & 0.13 & $0.44^{\mathrm{b}, \mathrm{c}}$ & 0.08 & $0.41^{\mathrm{a}, \mathrm{c}}$ & 0.06 \\
\hline DHGLA:LA & $0.22^{a}$ & 0.05 & $0 \cdot 25^{\mathrm{b}}$ & 0.04 & $0 \cdot 24^{b}$ & 0.06 & $0 \cdot 23^{a, b}$ & 0.05 \\
\hline AA:DHGLA & $8 \cdot 18^{a}$ & 1.88 & $8 \cdot 26^{a, b}$ & 1.98 & $8 \cdot 14^{a}$ & 1.78 & $8 \cdot 92^{b}$ & $2 \cdot 14$ \\
\hline
\end{tabular}

DHA, docosahexaenoic acid; AA, arachidonic acid; DHGLA, di-homo- $\gamma$-linolenic acid; LA, linoleic acid.

${ }^{\mathrm{a}, \mathrm{b}, \mathrm{c}}$ Mean values within a row within unlike superscript letters were significantly different $(P<0.05)$.

${ }^{*}$ For details of subjects and procedures, see pp. 790-792. 


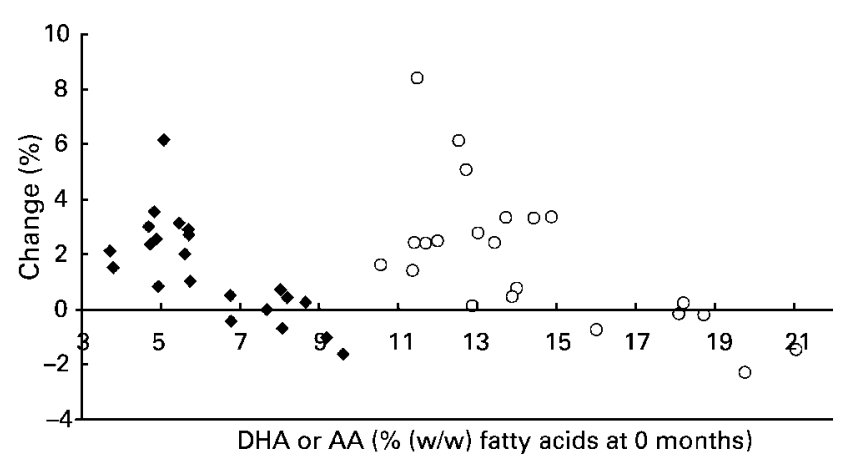

Fig. 1. Individual variations of docosahexaenoic acid (DHA; $\diamond)$ and arachidonic acid (AA; $O$ ) in erythrocyte membrane fatty acids after 3 months. Each point corresponds to one subject's values of DHA or AA; it has for the abscissa the percentage of DHA or AA at the beginning of the study, and its ordinate is the variation of the corresponding percentage after 3 months of supplementation. DHA regression curve, $y=-0.759 x+6.211(R 0.738)$; AA regression curve, $y=-0.55 x+9.803(R 0.658)$.

$<1 \%$. In the case of erythrocytes, as with plasma, the DHGLA, AA and DHA data show the highest ratios of increased cases; 18:22, 17:22 and 18:22 respectively.

\section{Discussion}

The main aim of the present study was to evaluate, in an elderly, institutionalised population, the biological effects of the consumption of a small amount of DHA, almost devoid of EPA, (DHA:EPA > 9), in the form of egg-yolk lipids. The choice of the dose $(100-150 \mathrm{mg} / \mathrm{d})$ was dictated by two factors. First, in Western countries egg consumption averages $0 \cdot 8-1 / \mathrm{d}$ and this amount of DHA can be found in an enriched egg (Surai et al. 2000) and second, the French RDA for DHA is $120 \mathrm{mg}$ for an adult and $100 \mathrm{mg}$ for elderly individuals (Martin, 2001). A long period of supplementation (9 months) was used. The study focused on blood parameters, plasma lipids and the fatty acid composition of plasma and erythrocyte membranes.

At the beginning of the study, the twenty-three analyses of fatty acids in erythrocyte membranes showed that DHA and AA contents were lower than but close to those reported in other studies for control groups of young individuals (Horrobin, 1997) and to that of a group of young healthy individuals we used as controls (Fig. 2). The average DHA:AA ratio reached 0.41 for the institutionalised elderly subjects while values of 0.38 to 0.44 have been calculated for younger controls (Horrobin, 1997; Peet et al. 1998). It is noteworthy that in pathological situations where fatty acid desaturases are depressed, such as in the case of diabetes (Horrobin, 1997), DHA is much more decreased than AA leading to a low DHA:AA ratio as illustrated in Fig. 2. This situation may be explained by the fact that the $\Delta 6$-desaturase, the rate-limiting enzyme in fatty acid desaturation, is involved twice in DHA biosynthesis as proposed by Sprecher et al. (1995). Hence in our case the slightly lower average concentration in DHA and AA in erythrocytes observed at the beginning of the study might be related to altered food choices rather than to a low $\Delta 6$-desaturase activity, which would have affected the DHA:AA ratio. These results are in line with those of Sprecher (1992), and support the conclusion that the fatty acid status of elderly individuals is more dependent on nutritional status than on a chronic defect in desaturase activities (Asciutti-Moura et al. 1988).

No significant difference was detected in blood lipid composition between the two groups of individuals analysed at the beginning of the study and at the end of the inclusion period, 6 months later (Table 3). Furthermore their average values showed no significant difference with those corresponding to the 0 -month time of the intervention group which represent the averages of values determined all along this 6-month period of time. This observation supports the fact that the 0-month time data might be considered as control values.

Following supplementation, no change in the average cholesterol concentration was observed even though the participants had an extra daily average intake of $200 \mathrm{mg}$ cholesterol. In the erythrocyte membranes, the fact that the DHGLA:linoleic acid ratio increased (Table 6) supports the conclusion that the DHA supplementation did not inhibit $\Delta 6$-desaturase activity. In addition, the AA:DHGLA ratio indicates that the activity of $\Delta 5$-desaturase was not inhibited by supplementation. The continuous increase in AA concentration is highly intriguing since usually a decrease in AA is associated with an increase in dietary n-3 PUFA (Carlson et al. 1992; Nelson et al. 1997; Vidgren et al. 1997; Wensing et al. 1999). Taking into account

Table 7. Variations at 3 months in individual plasma and erythrocyte membrane fatty acids* $^{*}$

\begin{tabular}{lllllrr}
\hline Fatty acid & Regression curve & $n$ & $R$ & $P$ & $\Delta>0$ & $\Delta<0$ \\
\hline Plasma & & & & & & \\
$20: 3 n-6$ & $y=-0.682 x+1.64$ & 21 & 0.542 & 0.0112 & 17 & 3 \\
$20: 4 n-6$ & $y=-0.117 x+1.654$ & 21 & 0.091 & 0.6937 & 16 & 5 \\
$20: 5 n-3$ & $y=-0.735 x+0.884$ & 21 & 0.542 & 0.0111 & 13 & 8 \\
$22: 5 n-3$ & $y=-1.163 x+1.822$ & 21 & 0.854 & $<0.0001$ & 11 & 10 \\
$22: 6 n-3$ & $y=-0.924 x+3.316$ & 21 & 0.909 & $<0.0001$ & 15 & 6 \\
Erythrocyte membranes & & & & & \\
$20: 3 n-6$ & $y=-0.426 x+1.002$ & 22 & 0.529 & 0.0113 & 18 & 4 \\
$20: 4 n-6$ & $y=-0.55 x+9.803$ & 22 & 0.658 & 0.0009 & 17 & 5 \\
$20: 5 n-3$ & $y=-1.225 x+1.61$ & 22 & 0.669 & 0.0007 & 14 & 8 \\
$22: 5 n-3$ & $y=-4.018 x+4.018$ & 22 & 0.481 & 0.0235 & 16 & 6 \\
$22: 6 n-3$ & $y=-0.759 x+6.211$ & 22 & 0.738 & $<0.0001$ & 18 & 4 \\
\hline
\end{tabular}

${ }^{*}$ For details of subjects and procedures, see pp. 790-792. 


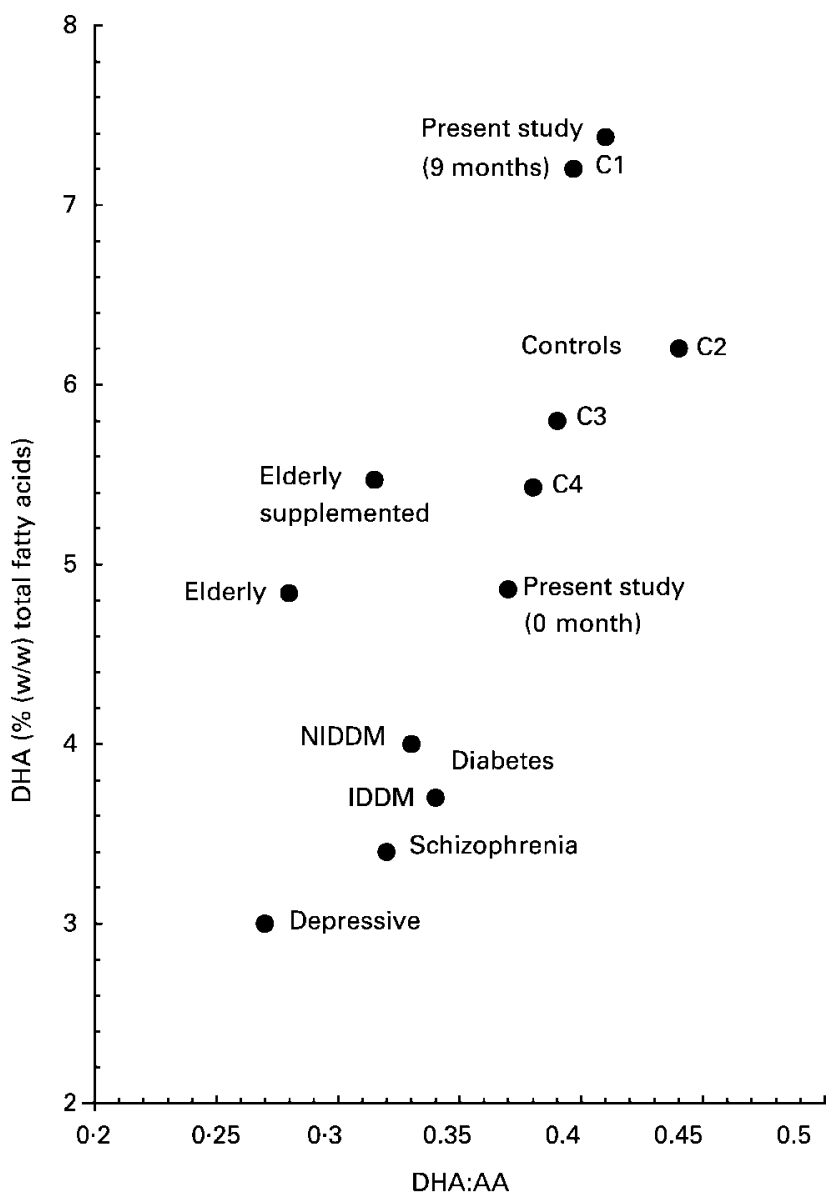

Fig. 2. Docosahexaenoic acid (DHA) v. DHA:arachidonic acid (AA) ratio in erythrocyte membrane lipids. The various values represent the data of: the present study at 0 months and 9 months and that of a control group of young healthy individuals (C2); elderly and supplemented elderly subjects (Rodriguez-Palmero et al. 1997); insulin-dependent diabetes mellitus (IDDM), insulin-dependent diabetes mellitus (NIDDM) and control subjects (C3) (Horrobin, 1997); depressive patients and control subjects (C4) (Peet et al. 1998); schizophrenia patients and control subjects (C1) (Laugharne et al. 1996).

the fact that the regular diet supplied an average of $100 \mathrm{mg}$ AA, one might consider that the extra average daily amount of $50 \mathrm{mg}$ AA might explain the continuous increase during the study. This interpretation leaves unexplained the increased proportion of DHGLA in plasma and erythrocytes. DHGLA which is not present in the supplementation (Table 1) cannot be generated in significant amounts by retroconversion from AA (Wijendran et al. 2002), in contrast to EPA from DHA (Brossard et al. 1996). Hence one may hypothesise that the observed increases in DHGLA (Tables 5 and 6) result from greater $\Delta 6$-desaturase activity, as indicated by the DHGLA:linoleic acid ratio, leading to the production of higher amounts of AA and DHA. It is noteworthy that 3 months after the supplementation was stopped the percentage of DHGLA in erythrocytes decreased (data not shown). Hence the observed increases in AA would result from a combination of an increased dietary supply (about $50 \mathrm{mg} / \mathrm{d}$ ) and an increased endogenous synthesis. The improvement in DHA status was accompanied by an increase in the AA percentage in plasma and erythrocyte fatty acids; this resulted in a significant increase in the PUFA content of the erythrocyte membrane $(+21.5,+23.6$ and $+25.3 \%$ at 3,6 , and 9 months respectively). This increase in PUFA content is rather unusual when compared with data from other studies which report small increases in PUFA following DHA supplementation in the form of triacylglycerols. For example, Vidgren et al. (1997) reported a $1 \%$ increase after 14 weeks, and Rodriguez-Palmero et al. (1997) reported a $2 \%$ increase after 15 months. Small decreases, even, have been noted by Nelson et al. (1997) (4\% after 90 d) and by Wensing et al. (1999) (3\% after 6 weeks). Our data are similar to those of a recent study which reports in the aged rat that feeding DHA-enriched egg phospholipids induces an increase in the proportion of AA in brain lipids, not due to direct supplementation (Favreliere et al. 2003).

These data support the conclusion that supplementation with DHA at approximately the French RDA in the form of egg lipids induces a significant change in the blood lipid content of DHA and AA in an elderly Mediterranean population. This increase in DHA and AA results in an increase in the PUFA content of erythrocyte membranes. The mechanism of such accretion of PUFA in blood lipids seems to result, on one hand, directly from dietary supplementation and, on the other hand, indirectly from a normalisation of lipid metabolism involving a better functioning of desaturases as illustrated by the increased levels of DHGLA. Such an observation does not preclude that large-scale studies will be necessary to assess the health effects associated with this change in lipidic status.

\section{Acknowledgements}

The present study was supported by the 'Conseil régional des Bouches du Rhône', la 'Région PACA' and 'Les Repas Santé'. The authors thank Patrice Berthèzene and Guillaume Haquette for their help in the statistical analyses, the nurses of the 'Centre Gérontologique Départemental' for their assistance in the study, as well as all the participants, and Charles Mansbach for his help in preparing the manuscript.

\section{References}

Asciutti-Moura LS, Guilland JC, Fuchs F, Richard D \& Klepping J (1988) Fatty acid composition of serum lipids and its relation to diet in an elderly institutionalized population. Am J Clin Nutr 48, 980-987.

Bernard C (1995) Préparation de glycérophospholipides enrichis en acide docosahexaénoïque (Preparation of docosahexaenoic enriched glycerophospholipids). Etude de leurs effets chez le lapin néozélandais hypercholestérolémique (Study of their effects on hypercholesterolaemic New Zealand rabbit). PhD thesis, Aix-Marseille III. Université de Droit, d'Economie et des Sciences d'Aix-Marseille III, Marseille.

Bligh EG \& Dyer WJ (1959) Rapid method of total lipid extraction and purification. Can J Biochem Physiol 57, 911-917.

Brenner RR (1977) Regulatory function of delta6 desaturate key enzyme of polyunsaturated fatty acid synthesis. $A d v \operatorname{Exp}$ Med Biol 83, 85-101. 
Brossard N, Croset M, Pachiaudi C, Riou JP, Tayot JL \& Lagarde M (1996) Retroconversion and metabolism of [13C]22:6n-3 in humans and rats after intake of a single dose of [13C]22:6n-3-triacylglycerols. Am J Clin Nutr 64, 577-586.

Burdge GC, Jones AE \& Wootton SA (2002) Eicosapentaenoic and docosapentaenoic acids are the principal products of alpha-linolenic acid metabolism in young men. Br J Nutr $\mathbf{8 8}$, 355-363.

Carlson SE, Cooke RJ, Rhodes PG, Peeples JM \& Werkman SH (1992) Effect of vegetable and marine oils in preterm infant formulas on blood arachidonic and docosahexaenoic acids. $J$ Pediatr 120, S159-S167.

Carnielli VP, Verlato G, Pederzini F, Luijendijk I, Boerlage A, Pedrotti D \& Sauer PJ (1998) Intestinal absorption of longchain polyunsaturated fatty acids in preterm infants fed breast milk or formula. Am J Clin Nutr 67, 97-103.

Darcet P \& Driss F (1985) Apports et utilisations des acides gras essentiels chez les personnes âgées (Contibutions and utilisations of essential fatty acids in old people). In L'alimentation des Personnes Âgées, pp. 141-148. Paris, France: CERIN.

De Gomez-Dumm I \& Brenner RR (1974) Oxidative desaturation of alpha-linolenic, linoleic and stearic acids in human liver microsomes. Lipids 10, 315-317.

Dyerberg J, Barg HO, Stoffersen E, Moncada S \& Vane JR (1978) Eicosapentaenoic acid and prevention of thrombosis and atheosclerosis? Lancet 2 (8081), 117-119.

Favreliere S, Perault MC, Huguet F, De Javel D, Bertrand N, Piriou A \& Durand G (2003) DHA-enriched phospholipid diets modulate age-related alterations in rat hippocampus. Neurobiol Aging 24, 233-243.

Feinberg M, Favier JC \& Ireland-Ripert J (1991) Répertoire Général des Aliments. Table de Composition REGAL. Paris, France: Lavoisier.

Gudbjarnason S, Benediktsdottir VE \& Skuladottir G (1989) Effects of n-3 polyunsaturated fatty acids on coronary heart disease. Bibl Nutr Dieta 43, 1-12.

Horrobin D (1997) Essential fatty acid (EFA) metabolism in patients with diabetic neuropathy. Prostaglandins Leukot Essent Fatty Acids 57, 256.

Kates M (1972) Techniques in Lipidology: In Laboratory Techniques in Biochemistry and Molecular Biology pp. 351-353 [TS Work and E Work, editors]. North Holland: American: Elsevier.

Klepping J, Guilland JC, Fuchs F, Marcer I \& Houard-Malval M (1990) Recueil de Données sur la Composition des Aliments. Neuilly sur Seine, France: Centre d'Étude et d'Information sur les Vitamines.

Kyle DJ, Schaefer E, Patton G \& Beiser A (1999) Low serum docosahexaenoic acid is a significant risk factor for Alzheimer's dementia. Lipids 34, S245.

Laugharne JD, Mellor JE \& Peet M (1996) Fatty acids and schizophrenia. Lipids 31, Suppl., S163-S165.

Lemaitre-Delaunay D, Pachiaudi C, Laville M, Pousin J, Armstrong M \& Lagarde M (1999) Blood compartmental metabolism of docosahexaenoic acid (DHA) in humans after ingestion of a single dose of $\left[{ }^{13} \mathrm{C}\right] \mathrm{DHA}$ in phosphatidylcholine. J Lipid Res 40, $1867-1874$.

Martin A (2001) Apports Nutritionnels Conseillés pour la Population Française. Paris, France: Lavoisier.
Munro HN \& Danford DE (1989) Nutrition, Aging and the Elderly. New York: Plenum Press.

Nelson GJ, Schmidt PC, Bartolini GL, Kelley DS \& Kyle D (1997) The effect of dietary docosahexaenoic acid on plasma lipoproteins and tissue fatty acid composition in humans. Lipids 32, 1137-1146.

Ohta A, Mayo MC, Kramer N \& Lands WE (1990) Rapid analysis of fatty acids in plasma lipids. Lipids 25, 742-747.

Paganelli F, Maixent JM, Duran MJ, Parhizgar R, Pieroni G \& Sennoune S (2001) Altered erythrocyte $n$-3 fatty acids in Mediterranean patients with coronary artery disease. Int $\mathrm{J}$ Cardiol 78, 27-32.

Pawlosky R, Hibbeln J, Lin Y, Salem N Jr \& Burdge G (2003) Nutrition Discussion Forum. Br J Nutr 90, 993-995.

Peet M, Murphy B, Shay J \& Horrobin D (1998) Depletion of omega-3 fatty acid levels in red blood cell membranes of depressive patients. Biol Psychiatry 43, 315-319.

Pekiner B \& Pennock JF (1995) Fatty acids in plasma and red blood cell membranes in humans, rats, rabbits and dogs. Biochem Mol Biol Int 37, 221-229.

Rodriguez-Palmero M, Lopez-Sabater MC, Castellote-Bargallo AI, de la Torre-Boronat MC \& Rivero-Urgell M (1997) Administration of low doses of fish oil derived N-3 fatty acids to elderly subjects. Eur J Clin Nutr 51, 554-560.

Simopoulos AP (1991) Omega-3 fatty acids in health and disease and in growth and development. Am J Clin Nutr 54, $438-463$.

Song JH, Inoue Y \& Miyazawa T (1997) Oxidative stability of docosahexaenoic acid-containing oils in the form of phospholipids, triacylglycerols, and ethyl esters. Biosci Biotechnol Biochem 61, 2085-2088.

Sprecher H (1992) Long chain fatty acid metabolism. In Polyunsaturated Fatty Acids in Human Nutrition, pp. 13-24 [U Bracco and RJ Deckelbaum, editors]. New York: Raven Press.

Sprecher H, Luthria DL, Mohammed BS \& Baykousheva SP (1995) Reevaluation of the pathways for the biosynthesis of polyunsaturated fatty acids. J Lipid Res 36, 2471-2477.

Surai PF, MacPherson A, Speake BK \& Sparks NH (2000) Designer egg evaluation in a controlled trial. Eur J Clin Nutr 54, 298-305.

Van Elswyk ME (1997) Comparison of $n-3$ fatty acid sources in laying hen rations for improvement of whole egg nutritional quality: a review. Br J Nutr 78, Suppl. 1, S61-S69.

Vidgren HM, Agren JJ, Schwab U, Rissanen T, Hanninen O \& Uusitupa MI (1997) Incorporation of $n-3$ fatty acids into plasma lipid fractions, and erythrocyte membranes and platelets during dietary supplementation with fish, fish oil, and docosahexaenoic acid-rich oil among healthy young men. Lipids 32, 697-705.

Wells MA \& Hanahan DJ (1969) Phospholipase A from Crotalus adamanteus Venom. Methods in Enzymol 14, 178-184.

Wensing AGCL, Mensink RP \& Hornstra G (1999) Effects of dietary $n-3$ polyunsaturated fatty acids from plant and marine origin on platelet aggregation in healthy elderly subjects. $\mathrm{Br}$ J Nutr 82, 183-191.

Wijendran V, Lawrence P, Diau GY, Boehm G, Nathanielsz PW \& Brenna JT (2002) Significant utilization of dietary arachidonic acid is for brain adrenic acid in baboon neonates. $J$ Lipid Res 43, 762-767. 